\title{
A Multiscale-Based Approach to Understand Dendrite Deflection in Continuously Cast Steel Slab Samples
}

\author{
ARUNAVA SENGUPTA, BEGOÑA SANTILLANA, SEETHARAMAN SRIDHAR, \\ and MICHAEL AUINGER
}

\begin{abstract}
Dendrite bending angle measurements were conducted along two different directions on four steel slab samples collected from a conventional caster. The primary dendrites growing at the slab surface showed a transition in their growth direction as the distance from the surface increased. Numerical fluid flow simulation showed changes in the flow directions that might have caused the change in the growth direction. The bending angle measurements were also correlated with the casting process parameters. Thereafter, a multiscale approach was adopted to predict the dendrite deflection angles by correlating the macro-scale flow profile with the micro-scale bending angle formulation and subsequently corroborated with the industrial scale measurements.
\end{abstract}

https://doi.org/10.1007/s11661-021-06313-6

(c) The Author(s) 2021

\section{INTRODUCTION}

Sustainability within the highly competitive market producing thinner sections of high-quality grades requires a balance between product quality and production volume for an industrial manufacturing process. It creates a thrust to bridge the gap between theoretical science and its practical application. In today's world of high-quality steels produced via continuous casting process $^{[1]}$ and cast to near net shape, the material science community is constantly engaged in uncovering the details of an intricate relationship of the solidification structure ${ }^{[2]}$ (distribution and morphology of different phases) on process parameters like fluid flow. Control of cast micro-structure could eliminate subsequent thermo-mechanical processing steps. Stringent product quality requirements demand detailed information on this structure that influences the evolving composition profile (micro-scale, $10^{-6}$ to $10^{-5} \mathrm{~m}$ ) mechanism and how it relates to the final chemistry across the full dimension (macro-scale, $10^{-3}$ to $1 \mathrm{~m}$ ) of

ARUNAVA SENGUPTA was with the WMG, University of Warwick, Coventry, CV4 7AL, UK and is currently with the Research \& Development Division, Tata Steel Ltd., Jamshedpur, 831007, India. Contact e-mail: arunava.s@tatasteel.com BEGOÑA SANTILLANA is with the Tata Steel Research and Development, 4H-16, PO Box 10000, 1970 CA IJmuiden, The Netherlands. SEETHARAMAN SRIDHAR is with the School for Engineering of Matter, Transport \& Energy, Arizona State University, Tempe, AZ 85287, USA. MICHAEL AUINGER is with the WMG, University of Warwick. Contact e-mail: m.auinger@warwick.ac.uk

Manuscript submitted September 8, 2020; April 25, 2021.

Article published online May 27, 2021 the product. Abnormality in chemical composition across large section calls for costly post treatments and may often lead to product rejection.

During solidification in a continuous casting process, phase evolution takes place across different length scales giving rise to solidification structure. Thermodynamics of solute rejection at the micro-level in combination with casting process parameters defines the macrosegrega$\operatorname{tion}^{[3]}$ (at the scale of casting) and hence the final properties of the solid steel. Macro-scale fluid flow during continuous casting washes away the rejected solute ahead of the micro-scale solid/liquid interface giving rise to different undercooling levels at different positions of the moving solidification front. The interface tends to change its growth direction depending on the undercooling levels. This is called dendrite bending [4] which occurs during solidification towards the upstream direction under the action of incoming fluid flow. With the progress of solidification, the intensity of the flow effect will decrease, and the influence of diffusion will come into play, thereby affecting the growth direction and hence the macro-scale solute profile. A clear link between the phenomena happening at the micro-level (dendrite evolution) to that observed at the macro-level in the cast product is still missing. Linking the dendrite deflection with bulk flow and solidification speed of the moving front will provide an important context towards understanding the macrolevel of segregation in the cast product. The structural length scales of the phases that form during the continuous casting process range from few micrometres up to several millimetres in the several metres long cast 
steel slab, thereby defining its multi-scale nature. Different numerical techniques which were employed to model dendrite evolution during solidification are the front tracking method (also called the sharp interface method), phase field method, cellular automaton (CA), mesoscale modelling ${ }^{[5]}$ and mean-field approach, respectively. The front tracking model is a direct phase evolution approach where the spatial resolution and time step are chosen such that they scale with the smallest length and time scales. Phase field method ${ }^{[6]}$ is an implicit front tracking algorithm that mimics the solid/liquid interface as a thin continuous transition layer intermediate between the actual length scale of a physical interface $(\sim \mathrm{nm})$ and the structural length scales (several $\mu \mathrm{m}$ ) obtained in standard solidification castings. Being derived from continuum thermodynamic principles, the method accurately models the kinetics of phase evolution in the field of materials science. ${ }^{[7]}$ The cellular automaton $^{[8]}$ model coupled with the finite element heat flow calculations is used to visualize the grain structures during solidification. In mesoscale modelling, a dendrite is tracked by its envelope connecting the tips of the primary dendrites and thus, the local details of the inter-dendritic structure are not fully resolved. The mean-field approach ${ }^{[9]}$ also models the dendrite envelope, but the volume-averaged governing equations are solved by projecting the dendrite in one-dimensional space. To address the translation of micro-scale information into the macro-scale, a combined theoretical and experimental based multiscale approach is required to have an in-depth understanding of the continuous casting process that would be helpful for shop floor operators to mitigate product quality issues.

Takahashi et al. ${ }^{[10]}$ in their experiment with steel ingots, empirically showed that the dendrite bending is a function of the solidification speed and flow velocity. Thereby, knowing the macro-scale fluid flow, one can understand the extent of macrosegregation. Being empirical, the Takahashi ${ }^{[10]}$ correlation is not mathematically defined for velocities close to zero because of the logarithmic dependence. It means that the application is limited to the experimentally validated conditions and does not reflect the conditions accurately in an industrial caster. Also, the deflection angle can be both positive and negative because of the logarithmic dependence. Modelling-based investigations of the flow effect on solidification microstructure $\left.{ }^{\left[4,10^{-}\right.} 14\right]$ have emphasized mostly on the effect of inlet flow magnitude on dendrite bending and branching of dendrites. Esaka et al. ${ }^{[4]}$ used the inclined chill plate experimental technique to measure the deflection angles, whereas Takahashi et al. ${ }^{[10]}$ determined the fluid flow effect in steel ingots. Both $\mathrm{Zhu}$ et $a .^{[11]}$ and Liu et al. ${ }^{[12]}$ modelled the growth of single dendrite under forced flow condition in Al-Cu and Al-Si binary alloys, respectively. Barati et al. ${ }^{[14]}$ numerically investigated the dendrite solidification in $\mathrm{Ni}-\mathrm{Cu}$ binary alloy and observed that the growth of different arms depends on the preferred growth direction under the action of melt flow. There, is however, not much validation with industrial scale applications. In the previous work, Sengupta et al. ${ }^{[15]}$ modelled the transient nature of the interface growth direction at different undercooling levels under the action of incoming fluid flow for a Fe-C binary alloy. Thereafter, an anisotropy in interface energy-based improved relation, connecting flow velocity and growth speed with the dendrite bending angle, was proposed. Way back in 1975, Okano et al. ${ }^{[16]}$ published their work on dendrite bending angle measurements in steel slabs cast at a speed of $0.6 \mathrm{~m} / \mathrm{min}$ and also without the influence of electro-magnetic brake $^{[17]}(\mathrm{EMBr})$. Nowadays, most of the industrial slabs are cast at a higher casting speed for higher productivity, and thus, the casters are equipped with EMBr. The primary aim of EMBr is to ensure stable as well as calm fluid flow pattern within the mould and thus can influence the dendrite deflection pattern. The authors have not found enough literature where the dendrite bending angles in industrial steel slab samples $^{[18]}$ under the influence of $\mathrm{EMBr}$ have been reported.

It is very challenging to simultaneously measure the fluid flow profile and flow magnitude as well as the growth speed of the solidification front within a continuous casting mould at liquid steel temperatures. Literature $^{[19,20]}$ is available for experimental measurements of surface velocity fluctuations in the mould. To date, researchers have relied upon qualitative fluid flow profile estimation through several numerical models. ${ }^{[21,22]}$ Since industrial-scale high-temperature experiments are costly, hazardous and time-consuming, a validated process model can be a handy tool for quick process optimisation in improving the product quality during its production. A theoretical relation with the industrial application would be of benefit to the casting technologist in controlling the casting process parameters.

In the present work, dendrite bending angle measurements were performed along two different directions on four steel slab samples (with varying carbon contents) collected from a conventional slab caster under the influence of EMBr. Measurements were performed up to $30 \mathrm{~mm}$ from the slab surface. Macro-scale fluid flow within the continuous casting mould was used as an input for the proposed micro-/macro-coupling approach. Thereby, an attempt has been made to link the macro-scale fluid flow profile and the growth speed of the moving solidification front within the continuous casting mould with that of the phenomenon happening at micro-scale. The experimental dendrite deflection angles were found to fit better with the correlation developed by Sengupta et al. ${ }^{[15]}$ compared to the relation proposed by Takahashi et al. ${ }^{[10]}$ Thus, in the present work, with the help of a novel computer-aided approach, the fluid flow has been coupled to a phase-field method across different length scales to model an industrial process, followed by experimental validation. The physics of the phenomenon at the micro-scale has been captured by employing the phase-field method. Furthermore, by measuring the dendrite deflection angles in the cast steel slabs, the present work shows how the macro-scale fluid flow under the action of EMBr within the continuous casting mould can be quantified under different process conditions. 


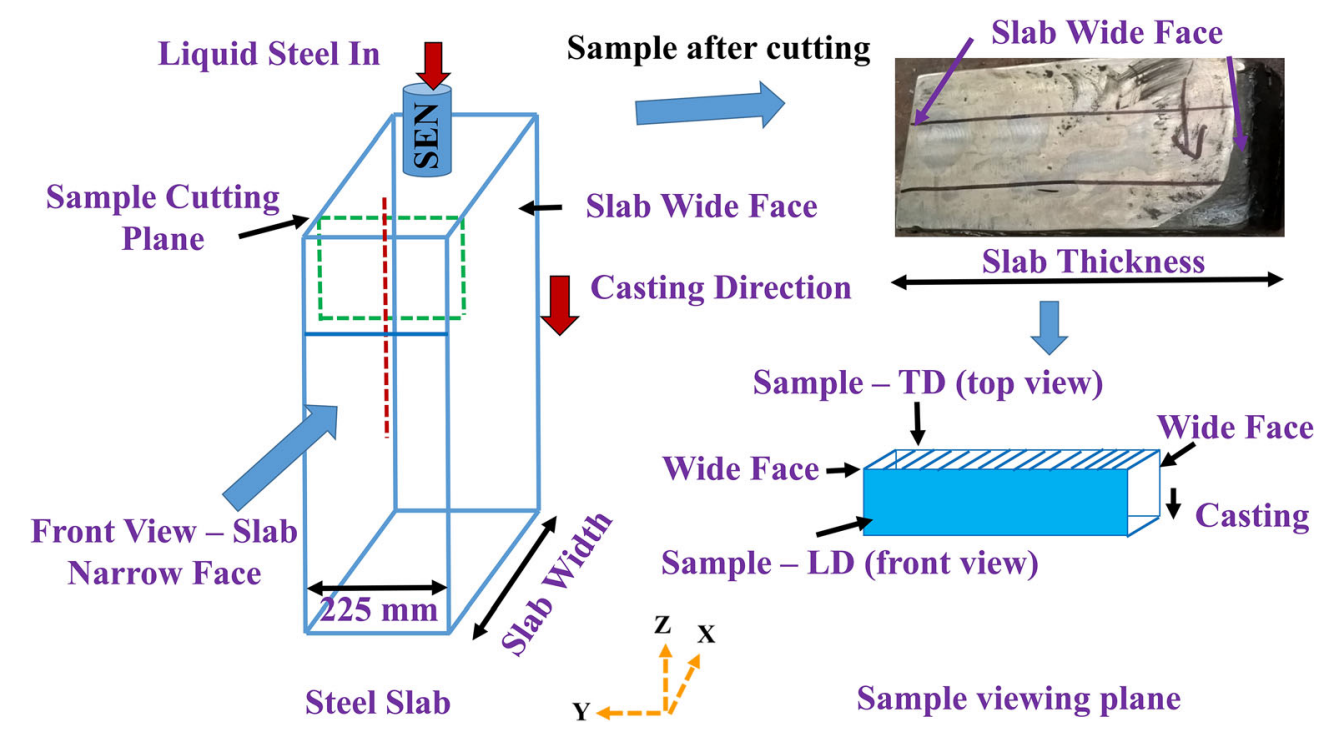

Fig. 1-Sample preparation scheme for the analysed steel slab samples.

Table I. Chemical Composition of the Industrial Slab Samples Used in This Study

\begin{tabular}{lccc}
\hline & \multicolumn{3}{c}{ Chemical Composition (Wt Pct) } \\
\cline { 2 - 4 } Sample & C & Mn & Fe \\
\hline A & 0.075 & 0.35 & bal. \\
B & 0.082 & 0.55 & bal. \\
C & 0.003 & 0.45 & bal. \\
D & 0.133 & 0.68 & bal. \\
\hline
\end{tabular}

\section{EXPERIMENTAL METHODOLOGY}

Four steel slab samples, collected from a conventional slab caster, were used in the present study. The scheme of sample collection is shown in Figure 1. The casting direction was along the $z$ direction, the $x$ direction being along the mould width, and the $y$ direction was along the slab thickness direction. The samples were cut approximately at a quarter distance inwards from the narrow face, i.e. along a plane $(y-z)$ parallel to the narrow face along the casting direction. The sample cutting plane was parallel to the narrow face. Samples after cutting from the slab resembled the one shown on the upper right corner (with two wide faces), which were cut further into small pieces of $35 \times 35 \times 10 \mathrm{~mm}$. The image on the lower right side shows the sample viewing planes.

Table I shows the chemical composition of the collected steel slab samples analysed through optical emission spectroscopy (OES). Sample A and sample B were low carbon grades, whilst sample $\mathrm{C}$ was an ultra-low carbon grade. Sample D was a medium carbon grade. All samples had similar manganese contents. The grades were selected to have minimal variation in the concentration of the elements other than carbon. From sample C to A, B and then to sample D, both the carbon and manganese contents increased though the variation in the manganese contents was not large. It has been reported that the dendrite bending angle increases with an increase in the solute carbon content. ${ }^{[4]}$

Table II shows the casting process parameters of the collected slab samples. All samples were cast with a stable casting speed except for sample D. Sample A was taken from a slab having a casting speed of $1.7 \mathrm{~m} / \mathrm{min}$ and width of $1300 \mathrm{~mm}$. Sample B and C were taken from slabs having similar casting speeds, but the slab corresponding to sample B had the highest width of $2100 \mathrm{~mm}$. All the samples were cast under the influence of a flow control device, i.e. ruler-type $\mathrm{EMBr}^{[12]}$ and the thickness of all the slabs was $225 \mathrm{~mm}$. The main objective of using EMBr nowadays in most of the industrial slab casters is to stabilize the turbulent flow within the mould region and reduce the meniscus fluctuations through the application of electromagnetic forces. Samples A, B and D were cast under the influence of single-ruler $\mathrm{EMBr}^{[17]}$ which had a single layer of the horizontal rectangular shaped magnetic field across the entire mould width. Sample $C$ was cast under the influence of double-ruler $\mathrm{EMBr}^{[17]}$ (also called FC-mould), which had two horizontal magnetic fields across the entire mould width - one above the submerged entry nozzle (SEN) port and the other below the SEN nozzle port.

Small samples from the collected slabs were mounted as per the standard metallographic procedure ${ }^{[23]}$ so that they could be used for subsequent steps of metallographic sample preparation. The Bechet-Beaujard etchant ${ }^{[24]}$ was used to reveal the dendritic structure. It was prepared by adding 17.6 grams of picric acid (solid moistened with 35 pct water since dry picric acid is hazardous) to $1000 \mathrm{ml}$ of water along with a small amount of soap solution as a wetting agent. About $0.5 \mathrm{pct}$ Teepol solution (sodium alkyl sulphonate) was added as a wetting agent. The wetting agent was added to clear out the surface from the residue of the etchant (reacted particles that come out while etching). Samples 
Table II. Casting Process Parameters of the Collected Slab Samples

\begin{tabular}{lcccc}
\hline Sample & Casting Speed, $/ \mathrm{min}$ & Superheat $\left({ }^{\circ} \mathrm{C}\right)$ & Width $(\mathrm{mm})$ & EMBr Current $(\mathrm{A})$ \\
\hline A & 1.7 & 23 & 1300 & 318 \\
B & 1.25 & 21 & 2100 & 418 \\
C & 1.19 & 42 & 1900 & -500 (bottom), 299 (top) \\
D & $0.76-1.55$ & 16 & 1600 & $43-518$ \\
\hline
\end{tabular}

were dipped in the etchant solution, and the top surface was constantly rubbed with cotton. After the etching was complete, the etched sample was observed under a Leica optical microscope for visualization of the dendritic solidification structure. To analyse large area and measure the bending angles of primary dendrites over a macroscopic region, an optical microscope was preferred over a scanning electron microscope (SEM). Dendrite growth results in 3D structures in the cast slab samples. Since it was difficult to measure the bending angle of dendrites in 3D, the microstructure analysis was performed along two different planes. At first, the bending angle was measured on the plane along the longitudinal direction (LD). The bending angle was also measured on the plane along the transverse direction (TD). For both cases, the measurement direction was from the slab surface towards the slab centre. With each selected dendrite as the diagonal, a rectangle was drawn. The deflection angle, corresponding to a dendrite, was calculated by measuring the height and width of the rectangle for that dendrite only. The sign convention of bending angle measurement has been described elsewhere. ${ }^{[25]^{\circ}}$

\section{RESULTS AND DISCUSSION}

\section{A. Fluid Flow Profile}

Based on an already existing fluid flow model, ${ }^{[26]}$ the fluid flow profile within the continuous casting mould corresponding to the casting process parameters of the collected slab samples was extracted and used as an input for the subsequent micro-macro-coupling. It is worthwhile to mention that the development of the finite volume model and the simulations were performed by somebody else. ${ }^{[26]}$ The computational domain for modelling the fluid flow included continuous casting mould, SEN with slide gate control and a simplified tundish to maintain a ferro-static pressure above the SEN. The steel meniscus in the mould was modelled as a free surface. The model included two-phase flow (argon and steel), magnetohydrodynamics (MHD), heat transfer and solidification. For solidification, the energy conservation equation was used, which considered the phase change during solidification. The solidified shell was assumed to move at a velocity equal to the casting speed. The shear stress turbulence model (SST) model $[27,28]$ was used to account for turbulence. The model was based on ANSYS CFX. ${ }^{[2]}$ The molten steel entered the tundish and subsequently went into the mould under gravity. The level of molten steel was obtained by
Table III. Material Properties of Steel. ${ }^{[29]}$

\begin{tabular}{lll}
\hline Property & \multicolumn{1}{c}{ Value } & \multicolumn{1}{c}{ Unit } \\
\hline Density & 7100 & $\mathrm{~kg} / \mathrm{m}^{3}$ \\
Kinematic Viscosity & $1.0 \times 10^{-6}$ & $\mathrm{~m}^{2} / \mathrm{s}$ \\
Thermal Expansion Coefficient & $1.1 \times 10^{-4}$ & $\mathrm{~K}^{-1}$ \\
Thermal Conductivity & 39 & $\mathrm{~W} /(\mathrm{mK})$ \\
\hline
\end{tabular}

regulating the steel flow from the shroud into the tundish and the sliding gate position. To ensure that no transient structures affect flow results, all modelling cases were simulated for enough time so that a developed flow profile was reached. All the fluid flow simulation results were transient and averaged over the last $40 \mathrm{~s}$. Table III shows the material properties of the steel used in the CFD model. The slab thickness and mould length were taken as $225 \mathrm{~mm}$ and $900 \mathrm{~mm}$, respectively.

Figure 2(a) shows the averaged fluid flow profile (parallel to wide face, i.e. along $z-x$ plane) within the mould region for sample $A$. The casting direction was along the $z$ axis, while the $x$ axis represented the direction along the slab width. The casting speed was 1.7 $\mathrm{m} / \mathrm{min}$ (corresponding to sample A in Table II), and the mould width was $1300 \mathrm{~mm}$. The simulation results were performed by Kholmatov. ${ }^{[26]}$ Flow vectors represent the fluid flow direction. The liquid steel exits the SEN port at high velocity, which decreases towards the narrow face. One part of the flow after exiting the nozzle port is directed downwards. It hits the narrow face wall and travels downwards. Some part of this flow, after traversing downwards, may change its direction and travel upwards towards the SEN port bottom. The other part of the flow exiting the nozzle part after hitting the narrow face walls travels upwards towards the meniscus. Thus, at one point, a transition in the flow direction ${ }^{[30]}$ from downward directed flow to upward meniscus directed flow may take place as one goes downwards along the casting direction. A similar flow pattern in continuous casting mould has also been reported ${ }^{[31,32]}$ with EMBr.

Figure 2(b) shows the velocity contours and flow vectors on a plane (shown in black colour) parallel to a narrow face. The cross section of the flow pattern shown in Figure 2(b) is arbitrary, and its main objective is to illustrate the change of flow direction. It seems from Figure 2(b) that at about $1 / 4$ th distance from the narrow face, the flow velocity increases from $0.06 \mathrm{~m} / \mathrm{s}$ close to the surface to about $0.3 \mathrm{~m} / \mathrm{s}$ in the zone of the 

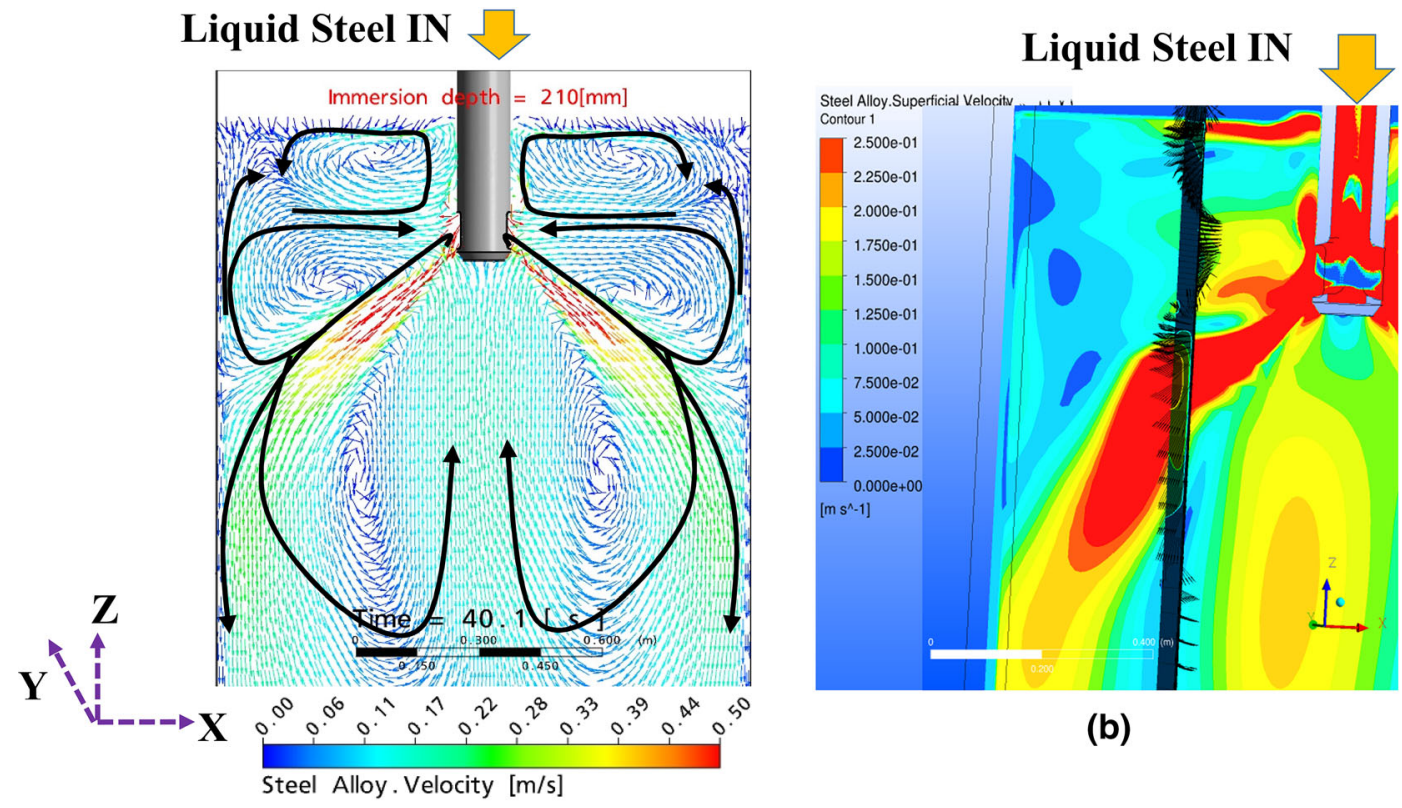

(b)

(a)

Fig. 2-Simulated fluid flow profiles [reprinted with permission from Ref. 26] in a continuous caster; (a) fluid flow profile for sample A; $(b)$ velocity magnitude and flow vectors on a plane parallel to the narrow face for sample A.

liquid steel jet. Further downwards, the velocity again decreases to about $0.1 \mathrm{~m} / \mathrm{s}$. Towards the meniscus, the flow is directed towards the narrow face, whilst at a bit further down, the flow is directed towards the SEN port. Even further downwards, the flow vectors can be seen to be moving out of the plane and directed towards the narrow face, while some vectors are seen to have a trend of upward-directed flow. Thus, going downwards along the $z$ direction parallel to the narrow face, it seems that at one point in the casting direction, there occurs a change in the flow direction. Having the fluid flow profile and growth speed at a position of the front, one can translate the information into the dendrite deflection angle.

\section{B. Micro-/Macro-Coupling}

In the previous work, the fit function based on the fluid flow and phase-field coupled solidification model proposed by Sengupta et al. ${ }^{[15]}$ is given as

$$
\begin{aligned}
\sin \theta= & \left(1-e^{-0.7551 \vec{\nu}^{0.6}}\right)\left(e^{-1.851 v_{t i p}^{0.01}}\right) \\
& +\left(1-e^{-0.3505 \vec{V}^{0.01}}\right)\left(e^{-8.753 v_{t i p}^{0.5}}\right)
\end{aligned}
$$

where $\theta$ is the dendrite bending angle in degrees, $\vec{V}$ is the maximum fluid velocity at the dendrite tip $(\mathrm{m} / \mathrm{s})$, and $v_{\text {tip }}$ is the tip growth speed $(\mathrm{m} / \mathrm{s})$. The bending angle was defined as the difference between the original interface growth direction in the absence of fluid flow and the deviated growth direction in the presence of fluid flow. Thus, the above equation represents the dependency of the micro-scale interface growth direction as a function of flow velocity and the tip (or interface) growth speed on the micro-scale. In this section, an attempt has been made in linking the fit function with the bulk fluid velocity and growth speed of the solidification front through micro-/macro-coupling.

The macro-scale fluid flow profile in a continuous casting mould for sample A is shown in Figure 2, which gives the magnitude of the flow velocity and flow direction at each point within the mould. Figure 3(a) shows the schematic of two different macro-scale shell thickness profiles $\left(\mathrm{S}_{1}\right.$ at a casting speed $v_{C 1}$ and $\mathrm{S}_{2}$ at a casting speed $v_{C 2}, v_{C 2}>v_{C 1}$ ) along the casting direction, growing over the mould wall with time. Going downwards along the casting direction, the shell thickness will increase. ${ }^{[33]}$ The higher the casting speed, the lower the shell thickness will become. ${ }^{[34]}$ The flow vectors, shown in blue colour in Figure 3(a), can be seen to hit the growing shell, shown in purple colour, at different points. Thus, the growing shell on the macro-scale can be viewed as the moving solidification front.

The projection of various points (as shown in Figure $3(\mathrm{a})$ ) on the growing shell in $x$ direction gives the value of shell thickness "S" from the slab surface. The projection of two such points along the $x$-axis, as indicated by the black dashed lines in Figure 3, gives the shell thickness values of $x_{1}$ and $x_{2}$, respectively. Thus, each point on the growing shell for different casting speeds can be translated as the distance from the slab surface towards the centre along the $x$ axis. For each such point on the shell, the average macro-growth speed of the moving front and the macro-scale fluid flow profile can be derived from simulations. These macroscale values can be plugged into the fit function (Eq. [1]) to estimate the interface growth direction.

The fluid flow profile corresponding to sample A was retrieved for a casting speed of $1.7 \mathrm{~m} / \mathrm{min}$, EMBR current strength of $237 \mathrm{~A}$ and casting width of $1300 \mathrm{~mm}$, 

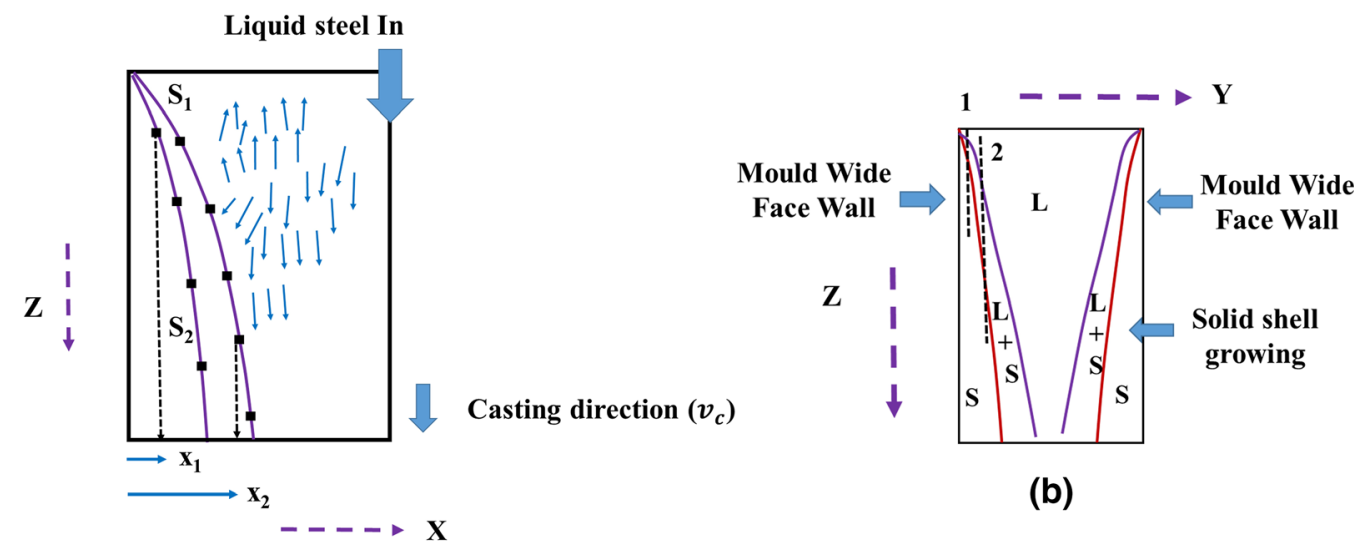

(a)

Fig. 3-(a) Macro-scale shell thickness profiles $\left(\mathrm{S}_{1}\right.$ and $\left.\mathrm{S}_{2}\right)$ growing over mould wall during continuous casting process; $(b)$ schematic of solid shell growing over mould wall and estimation of flow velocity along vertical direction.

respectively. Similarly, for sample C the flow profile was retrieved for a casting speed of $1.2 \mathrm{~m} / \mathrm{min}$ and double ruler EMBR current strength of -500 A / 300 A, respectively. From the fluid flow profile of sample A, a plane at $1 / 4$ th distance from the narrow face wall was selected as the sample cutting position. Figure 3(b) shows the $y-z$ plane parallel to the narrow face. The steel shell will grow away from both wide face walls. Several vertical lines along the thickness direction ( $y$ direction) and specific distances from the slab surface were selected. In Figure 3(b), two vertical (black dashed) lines were drawn at different distances from one of the mould wide face wall. The purple line indicates the liquidus line, and the brown line indicates the solidus line. Going downwards along the black dashed line along the casting direction, the initial portion of the line will be 100 pct liquid. Below the liquidus line, the solid fraction will increase continuously, and at the solidus line, the solid fraction will be 100 pct. At any vertical distance from the top, the distance of the solidus line from the mould wide face wall (along $y$ direction) is the solid steel shell thickness. For example, the dendrite bending angle for sample A was measured at $6.5 \mathrm{~mm}$ from the surface. The corresponding vertical distance from the meniscus for a shell thickness of $6.5 \mathrm{~mm}$ was estimated from the CON1D model developed by B. G. Thomas et al. ${ }^{[33]}$ This model predicts the shell thickness profile as a function of casting parameters. Thus, the vertical distance from the meniscus corresponding to shell thickness of $6.5 \mathrm{~mm}$ was estimated as $220 \mathrm{~mm}$. It may be appropriate to mention that the dendrites growing at $6.5 \mathrm{~mm}$ from the surface will get deflected due to the flow velocity in the two-phase region $(\mathrm{S}+\mathrm{L})$ rather than the flow velocity in the fully liquid zone. In the present work, the dendrite deflection was assumed to be a function of flow velocity in the fully liquid zone. The vertical line along the casting direction that showed 100 pet liquid at $220 \mathrm{~mm}$ from the meniscus was selected. Going downwards along that vertical line, at $220 \mathrm{~mm}$ from the meniscus, the magnitude of the velocity components was derived from the numerical fluid flow model. The average solidification rate for the shell thickness of $6.5 \mathrm{~mm}$ was determined from the CON1D ${ }^{[33]}$ model. In the present study, the macro-scale solidification rate (or shell growth rate) at a distance from the CON1D model has been assumed to be equal to the micro-scale interface growth speed growing at the same distance. The corresponding growth rate and flow velocity were put into the fit function as well as into the relation proposed by Takahashi et al. ${ }^{[10]}$ Then, the deflection (or bending) angles were estimated. These estimated deflection angles were then compared with the experimentally measured ones.

\section{Dendrite Bending Angle Measurements}

Figure 4(a) shows the dendrite growth direction (along LD, i.e. $y-z$ plane) for sample $\mathrm{C}$ at a distance away from the surface, and Figure 4(b) shows the dendrite growth direction close to the slab surface (casting direction downwards). At the surface (figure 4(b)), some of the primary dendrites were inclined in the downward direction, while the rest (marked as white/blue dashed lines) were inclined in the upward direction. It is to be noted that the white/blue dashed lines are the direction of the measured dendrites. Thus, they show a tendency of transition in the growth direction from downwards to upwards. Further away from the surface, most of the primary dendrites, marked as white dashed lines, were oriented upwards. A similar observation was also reported by Sengupta et al. ${ }^{[25]}$ The change ${ }^{[30]}$ of fluid flow direction, as shown in Figure 2, might have affected the change in the dendrite growth direction, which thus validates the modelled flow profile.

Figure 5(a) shows the dendrite growth direction (along TD, i.e. $x-y$ plane) for sample $\mathrm{B}$ at a distance away from the surface, and Figure 5(b) shows the dendrite growth direction close to the slab surface. At the surface, some of the primary dendrites (marked as white broken lines) were inclined in the downward direction, while the rest were inclined in the upward direction. Thus, they show a tendency of transition in the growth direction from downwards to upwards. At a further distance away from the surface, most of the 


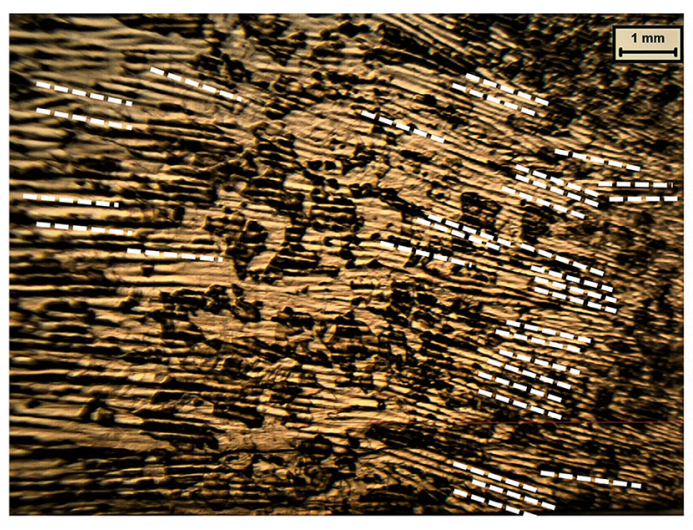

(a)

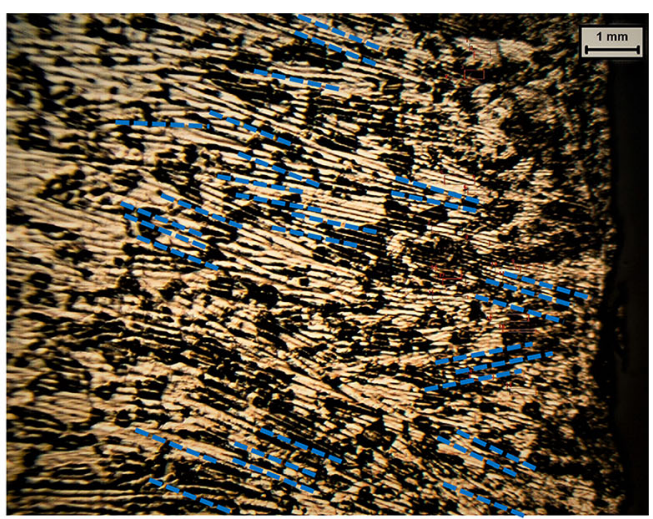

Slab Surface 1

Fig. 4-Dendrite growth direction; (a) away from the slab surface for sample C; $(b)$ close to the slab surface for sample C.

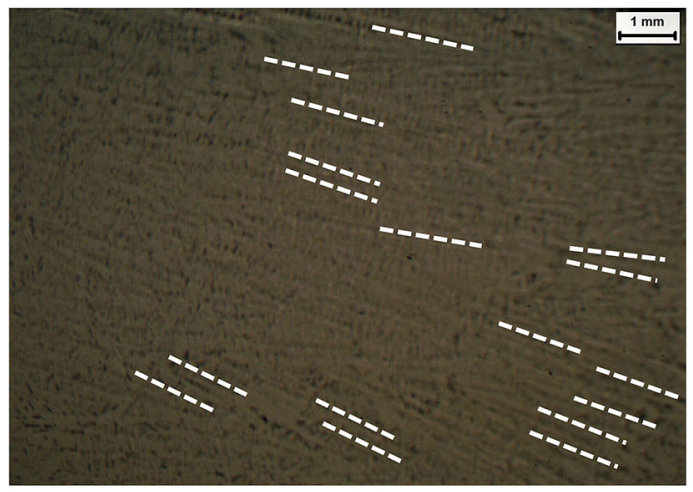

(a)

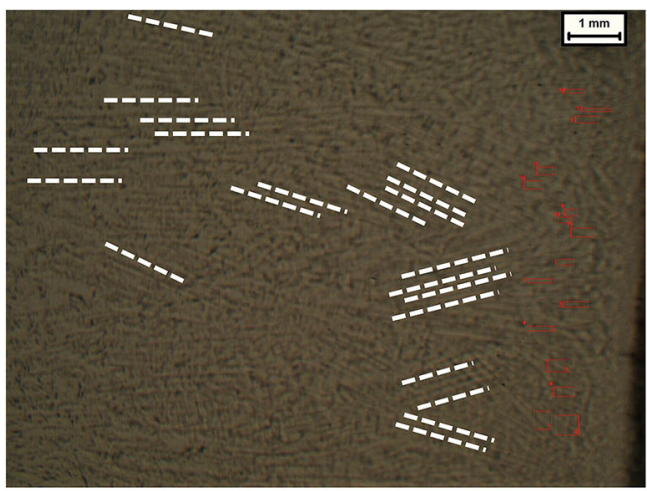

(b)

Fig. 5-Dendrite growth direction; (a) away from the slab surface for sample B; $(b)$ close to the slab surface for sample B.

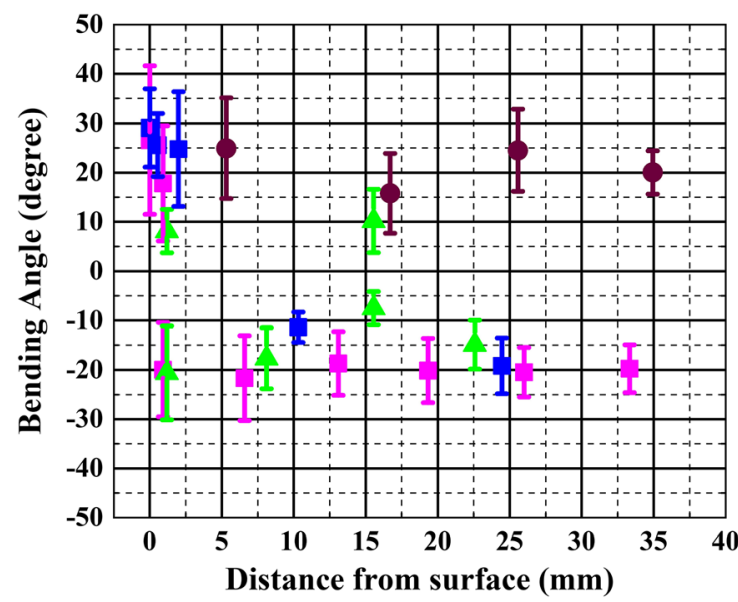

(a)

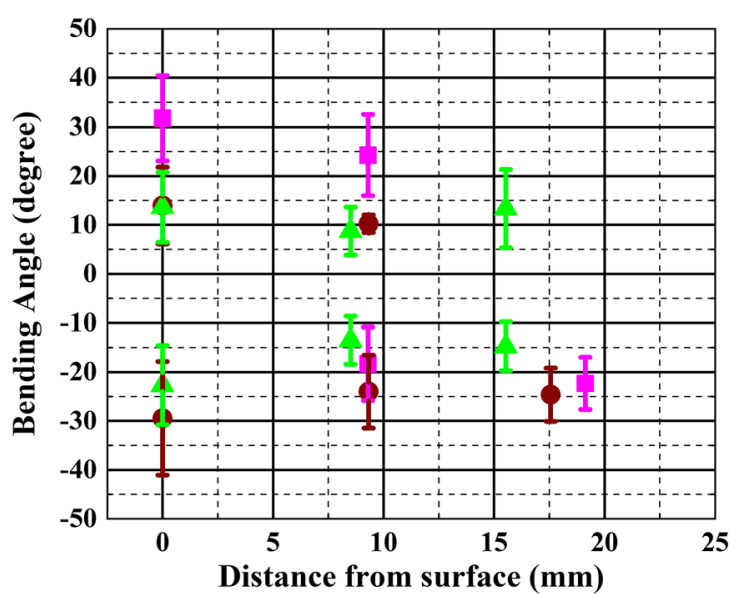

(b)

Fig. 6-Variation in the dendrite bending angle for the slab samples (a) along LD; $(b)$ along TD: Sample A $1.7 \mathrm{~m} / \mathrm{min} 1300 \mathrm{~mm}$ LD (pink square), Sample_B_1.25 m/min_2100 mm_LD (brown circle), Sample_C_1.19 m/min_1900 mm_LD (green triangle) and Sample_D_0.76 to 1.5 $\mathrm{m} / \mathrm{min} \_1600 \mathrm{~mm} \_$LD (blue square) (Color figure online). 
primary dendrites (marked as white broken lines) were oriented upwards. This indicated a possible transition in the fluid flow profile occurring within the mould.

Figure 6(a) shows the variation in the dendrite bending angle for all the slab samples along LD up to about $30 \mathrm{~mm}$. For sample A close to the surface, the dendrite bending angle was positive, i.e. all the primary dendrites were oriented along the same downward direction. At a small distance, away from the surface, the bending angles were found to be both positive and negative, indicating the transition phase of the flow direction. At a further distance away from the surface, the dendrite bending angle was negative, indicating all the primary dendrites were oriented in a direction opposite to what they were at the slab surface. Thus, the flow direction within the mould at this point was in the opposite direction to what was observed close to the meniscus. The mean value of the bending angle was almost constant after about $5 \mathrm{~mm}$ away from the surface. A similar transition of the bending angle was observed for sample D as well, which was cast under variable casting speed. The dendrite bending angle of sample B showed an interesting pattern. All the dendrite bending angles were found to be positive up to $35 \mathrm{~mm}$ from the surface, i.e. no change in the growth direction was observed. It is to be noted that compared to sample A, sample B was cast at a lower casting speed of $1.25 \mathrm{~m} /$ min and at a much higher mould width of $2100 \mathrm{~mm}$. It is reported $^{[22]}$ that an increase in mould width enables the liquid steel jet to hit the narrow face walls at lower positions. Also, the EMBr current strength for sample B was 418A, while that for sample A was 318A. Higher $\mathrm{EMBr}$ current strength forces the liquid steel jet to bend downwards ${ }^{[35]}$ and hit the narrow face walls at the lower position. Thus, one would expect the flow transition in sample B to happen at a further distance away from the narrow face, i.e. at a higher value of shell thickness. Sample C was cast at a casting speed of $1.19 \mathrm{~m} / \mathrm{min}$. Also, sample $\mathrm{C}$ was an ultra-low carbon grade, while the other samples had higher carbon content. It has been reported $^{[4,36]}$ that higher solute content causes more asymmetrical solute profile and higher deflection of the

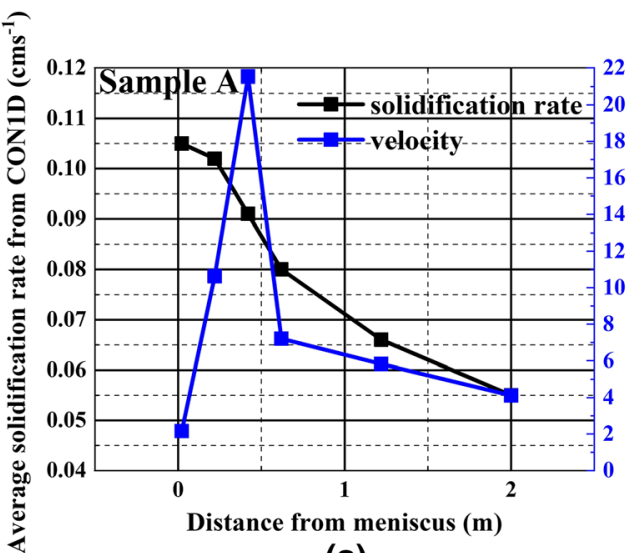

(a)

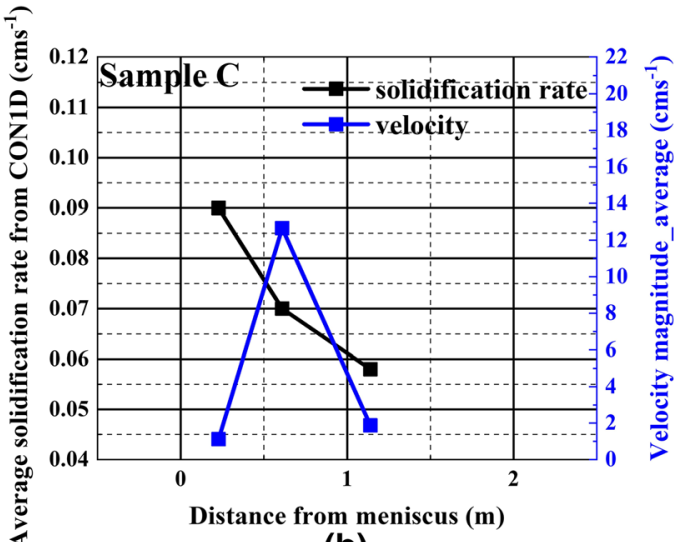

(b)

Fig. 7-Variation of solidification rate and velocity magnitude with distance from meniscus; $(a)$ sample A; $(b)$ sample C.

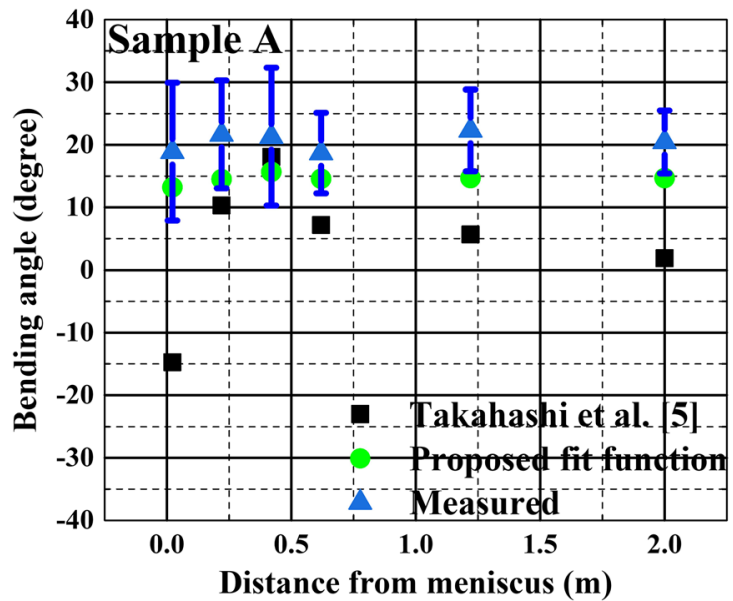

(a)

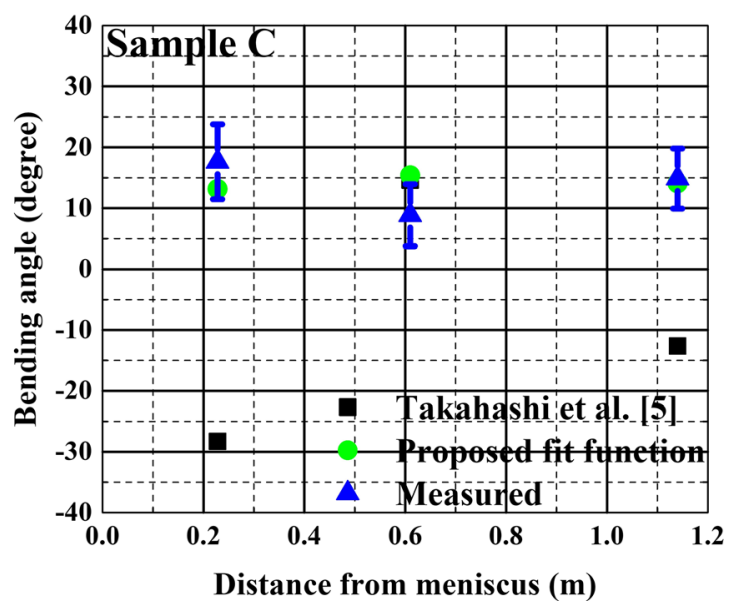

(b)

Fig. 8-Comparison of experimentally measured bending angle with Takahashi ${ }^{[10]}$ correlation and proposed fit function; $(a)$ sample A; $(b)$ sample C. 
dendrites. Both carbon and manganese will have a similar effect on the dendrite deflection angle, i.e. higher solute content will increase the deflection angle. This may be considered to have resemblance in the way carbon and manganese influence the hardenability ${ }^{[37]}$ in steels, i.e. both increases the hardenability which is governed by the carbon equivalent (CE) formula. Carbon equivalent relates the effect of alloying elements to a proportionate amount of carbon in steels towards hardenability. One of the commonly used expressions ${ }^{[37]}$ equates $1 \mathrm{wt}$ pct carbon to $(1 / 6) \mathrm{wt}$ pct of manganese, respectively. In line with this, it can be said that the carbon equivalent increases from sample $\mathrm{C}$ to $\mathrm{A}, \mathrm{B}$ and it is highest for sample D. Hence, a term "solute equivalent" synonymous to "carbon equivalent" can be designated to indicate the effect of different alloying elements towards the dendrite deflection angles. Thus, potentially because of the least solute equivalent (both carbon and manganese) contents, the mean values and the spread of the bending angle were found to be least for sample $\mathrm{C}$ among all the slab samples. Also, the bending angles for sample B and A were found to be more than that of sample $\mathrm{C}$, respectively. The standard deviation of the dendrite bending angle was found to be higher at the surface and decreased towards the centre. This may be because the bulk fluid flow becomes more uniform, and the velocity magnitude decreases in the casting direction towards the mould exit, as shown in Figure 2(a).

The contribution of the dendrite bending angle along TD will be dominantly from the $x$ component of the velocity which is the velocity component along the mould width direction. Dendrite bending angle along TD (Figure 6(b)) was measured for samples A, B and C, respectively. For sample A away from the surface, the dendrite bending angle changed sign from positive to negative, indicating a possible transition in the flow direction like that observed along LD. Comparatively, lower bending angle values of sample $\mathrm{C}$ to that of sample B may be due to the lower carbon content of sample C. In Figure 6(b) also, the standard deviation and mean values of the dendrite bending angle were higher at the surface and decreased away from the surface.

\section{Comparison of Dendrite Bending Angles}

Based on the micro-/macro-coupling, as mentioned in Section III-B, Figure 7(a) shows the variation of solidification rate (from CON1D) and velocity magnitude with distance from the meniscus for sample A. The solidification rate was the highest close to the meniscus and steadily decreased with distance from the meniscus along the casting direction. The range of solidification rates in Figure 7(a) was similar to that of the reported ${ }^{[38]}$ dendrite growth rates in the continuous casting process. The velocity magnitude close to the surface was low, and then, it increased up to a certain distance from the meniscus. The point where this increase in velocity occurs may be close to the liquid steel jet exiting the
SEN port. Going further downwards, the flow velocity was found to decrease. The velocity magnitude obtained was found to be similar to that reported by Xu et al. ${ }^{[32]}$ Figure 7(b) shows the variation of solidification rate and velocity magnitude with distance from the meniscus for sample C. The solidification rate decreased with distance from the meniscus along the casting direction.

Figure 8(a) shows the comparison of experimentally measured bending angles with that obtained from the Takahashi ${ }^{[10]}$ correlation, and the fit function for sample A. The same procedure for sample $\mathrm{C}$ is shown in Figure 8(b), respectively. At a specific distance from the meniscus, the modelled growth speed of the solidification front and the flow velocity ahead of the front were assumed to be constant. The modelled values were then put into the fit function to obtain the modelled bending angle. The estimated bending angles from the correlation agreed well to the experimental data, while the data from the Takahashi relation do not. At relatively low flow velocities, the Takahashi relation predicts low bending angles with values even close to zero and negative in one of the cases, as shown in the figures. In this way, the experimentally measured dendrite growth direction can be useful in understanding the fluid flow direction existing within a continuous casting mould. Also, the variation in the magnitude of the measured dendrite bending angles will give an estimate of the flow magnitude within the mould. Hence, an experimentally validated theoretical fit function can be useful to predict the fluid flow profile. The constants and the exponents of the fit function may change between different casters, but the model will still be able to show the trends.

\section{CONCLUSIONS}

In the present work, an industrial process was coupled with an advanced computational technique through a multiscale approach. Good agreement of fluid flow transition between the fluid flow simulations and the experimental measurement of dendrite deflection angles were obtained for the industrial slab samples from a conventional caster. The numerically modelled fluid flow profile qualitatively agreed well with the change in the dendrite growth direction observed in the continuously cast steel slab samples. The measured dendrite bending angles showed a transition in the growth direction with distance from the slab surface. Also, the standard deviation of the bending angle across the mean value decreased away from the slab surface. The modelled dendrite bending angles were found to be in good quantitative agreement with experimental measurements. Thus, the theoretical formulation is an improved version of the few available empirical correlations and can be extended to other systems to understand the influence of fluid flow. In this way, effective coupling of industrial scale measurements with advanced computational techniques can be a way forward to serve the purpose of quick process optimisation for different engineering conditions. 


\section{ACKNOWLEDGMENTS}

The present work was carried out as a part of PhD research project fully funded by Tata Steel UK Limited (A0425/GIPS 02650). The authors gratefully acknowledge Mr. Ergun Dogan for assistance in sample cutting and Mrs. Tu Phan Tran for assistance with the microstructural characterisation. The authors also gratefully acknowledge Dr. Daniel van Odyck and Ir. Dirk van der Plas for help in the numerical fluid flow simulations.

\section{OPEN ACCESS}

This article is licensed under a Creative Commons Attribution 4.0 International License, which permits use, sharing, adaptation, distribution and reproduction in any medium or format, as long as you give appropriate credit to the original author(s) and the source, provide a link to the Creative Commons licence, and indicate if changes were made. The images or other third party material in this article are included in the article's Creative Commons licence, unless indicated otherwise in a credit line to the material. If material is not included in the article's Creative Commons licence and your intended use is not permitted by statutory regulation or exceeds the permitted use, you will need to obtain permission directly from the copyright holder. To view a copy of this licence, visit http://creat ivecommons.org/licenses/by/4.0/.

\section{REFERENCES}

1. S. Louhenkilpi: Treatise on Process Metallurgy, Elsevier, Oxford, UK, 2014, vol. 3, pp. 373-434.

2. D. Senk, B. Engl, O. Siemon, and G. Stebner: Steel Res., 1999, vol. 70 , pp. $368-72$.

3. E.J. Pickering: ISIJ Int., 2013, vol. 53, pp. 935-49.

4. H. Esaka, F. Suter, and S. Ogibayashi: ISIJ Int., 1996, vol. 36, pp. $1264-72$.

5. A. Viardin, M. Zaloznik, Y. Souhar, M. Apel, and H. Combeau: Acta Mater., 2017, vol. 122, pp. 386-99.

6. S.G. Kim, W.T. Kim, and T. Suzuki: Phys. Rev. E, 1999, vol. 60, pp. 7186-97.

7. N. Provatas and K. Elder: Phase-Field Methods in Material Science and Engineering, 1st ed., Wiley, New York, 2010.

8. S. Luo, M. Zhu, and S. Louhenkilpi: ISIJ Int., 2012, vol. 52, pp. $823-30$

9. C. Sarkis: Material chemistry. Université Paris sciences et lettres, 2016.
10. T. Takahashi, K. Ichikawa, M. Kudou, and K. Shimahara: Tetsu-to-Hagane, 1975, vol. 61, pp. 2198-2213.

11. M.F. Zhu, T. Dai, S.Y. Lee, and C.P. Hong: Comput. Math. Appl., 2008, vol. 55 , pp. $1620-28$.

12. M.X. Liu, K. Wang, D. Xia, and T. Jiang: J. Alloys Compd., 2014, vol. 589, pp. 431-35.

13. L. Qiang, Y. Xiang-Jie, and L. Zhi-Ling: J. Appl. Sci., 2013, vol. 13 , pp. $2700-04$.

14. H. Barati, M.R. Aboutalebi, S.G. Shabestari, and S.H. Seyedein: Can. Metall. Q., 2011, vol. 50, pp. 408-15.

15. A. Sengupta, B. Santillana, S. Sridhar, and M. Auinger: JOM, 2019, vol. 71 (11), pp. 3876-84.

16. S. Okano, T. Nishimura, H. Ooi, and T. Chino: Tetsu-to-Hagané., 1975, vol. 61, pp. 2982-90.

17. S.-M. Cho and B.G. Thomas: Metals, 2019, vol. 9 (471), pp. 1-38.

18. X. Wang, S. Wang, L. Zhang, S. Sridhar, A. Conejo, and X. Liu: Metall. Mater. Trans. A, 2016, vol. 47A, pp. 5496-5509.

19. R. Liu, B.G. Thomas, J. Sengupta, S.D. Chung, and M. Trinh: ISIJ Int., 2014, vol. 54, pp. 2314-23.

20. T. Zhang, J. Yang, and P. Jiang: Metals, 2019, vol. 9 (36), pp. $1-15$.

21. B.G. Thomas and L. Zhang: ISIJ., 2001, vol. 41, pp. 1181-93.

22. B.G. Thomas, L.J. Mika, and F.M. Najjar: Metall. Trans. B., 1990, vol. 21, pp. 387-400.

23. G.F. VanderVoort: Metallography Principles and Practice, McGraw-Hill Book Co., New York, 1999.

24. S. Béchet and L. Beaujard: Rev. Métall., 1955, vol. 52, pp. 830-36.

25. A. SenGupta, B. Santillana, S. Sridhar, and M. Auinger: $I O P$ Conf. Ser. Mater. Sci. Eng., 2019, vol. 529, art. no. 012065.

26. S. Kholmatov: Tata Steel Research and Development, IJmuiden, The Netherlands, unpublished research, 2011.

27. M.I. HaqueSiddiqui and P.K. Jha: ISIJ Int., 2014, vol. 54 (11), pp. $2578-87$.

28. K. Timmel, X. Miao, T. Wondrak, F. Stefani, D. Lucas, S. Eckerta, and G. Gerbeth: Eur. Phys. J. Spec. Top., 2013, vol. 220, pp. $151-66$.

29. L. Zhong, M. Zeze, and K. Mukai: ISIJ Int., 2005, vol. 45, pp. $312-15$.

30. R. Chaudhary, B.G. Thomas, and S.P. Vanka: Metall. Mater. Trans. B., 2012, vol. 43B, pp. 532-53.

31. K. Jin, S.P. Vanka, and B.G. Thomas: Metall. Mater. Trans. B., 2018, vol. 49B, pp. 1360-77.

32. L. Xu, E. Wang, C. Karcher, A. Deng, and X. Xu: Metall. Mater. Trans. B., 2018, vol. 49, pp. 2779-93.

33. Y. Meng and B.G. Thomas: Metall. Mater. Trans. B., 2003, vol. 34B, pp. 685-705.

34. M. Sadat, A. Gheysari, and S. Sadat: Heat Mass Transf., 2011, vol. 47, pp. 1601-09.

35. K. Cukierski and B.G. Thomas: Metall. Mater. Trans. B., 2008, vol. 39B, pp. 94-107.

36. S.Y. Lee, S.M. Lee, and C.P. Hong: ISIJ Int., 2000, vol. 40, pp. $48-57$.

37. S. Talas: Mater. Des., 2010, vol. 31, pp. 2649-53.

38. M. Long, L. Zhang, and F. Lu: ISIJ Int., 2010, vol. 50, pp. 1792-96.

Publisher's Note Springer Nature remains neutral with regard to jurisdictional claims in published maps and institutional affiliations. 